\title{
Work in Progress: Hearing You Loud and Clear: the Student Voice as a Driver for Curriculum Change in a Chemical Engineering Degree Course
}

\section{Dr. Deesha Chadha, Imperial College London}

I currently work as a senior teaching fellow in the department of chemical engineering at Imperial College London having previously worked in academic development for a number of years at King's College London.

\section{Ms. Marsha Maraj, Imperial College London}

Marsha has been an educator in higher education for over 14 years. She is currently a Senior Strategic Teaching Fellow in the Department of Chemical Engineering at Imperial College London (ICL) where she teaches mechanical design to third-year chemical engineering students. She is enthusiastic about using collaborative approaches and student partnerships in the scholarship of learning and teaching. Her current educational research focuses on exploring the connections among peer learning, social capital and academic motivation.

Dr. Andreas Kogelbauer, Imperial College London

Dr. James Campbell, Imperial College London

Currently a teaching fellow at Imperial College London, Chemical Engineering Department

\section{Dr. Clemens Brechtelsbauer, Imperial College London}

Clemens Brechtelsbauer holds a degree and a doctorate in chemical engineering from Friedrich-Alexander University Erlangen-Nuremberg and worked for 13 years in primary pharmaceutical process development, first at SmithKline Beecham and later at GlaxoSmithKline before joining Imperial College London. His main educational research evolves around experiential learning, particularly participatory design, which takes techniques proven to be successful in modern project management and applies them to an educational setting. One key feature is involving students as major stakeholders in designing their own learning.

Dr. Colin Paul Hale,

Dr. Umang Vinubhai Shah, Imperial College London

Prof. Klaus Hellgardt, Imperial College London 


\section{Hearing you loud and clear: the student voice as a driver for curriculum change in a chemical engineering degree course (WIP)}

\section{Introduction}

A curriculum review can be an intricate and arduous process, made more complex due to a myriad of interwoven threads that inform the curriculum. This is often the case in chemical engineering due in part to the accommodation of employer expectations, requirements from accreditation bodies and the multidisciplinary, integrative nature of an engineering degree which depends on students acquiring a wide range of attributes, and which focuses on application and relevancy [1], [2]. In this paper, we present our efforts to review the chemical engineering curricula at a research-intensive higher education institution (HEI) in the UK. This review is being orchestrated by institutional managers to ensure that programmes of study throughout the HEI better reflect student needs and expectations and adhere to a recently revised institutional teaching and learning strategy. This review is also driven by a recognition that the student body has changed with traditional modes of teaching seemingly outdated and ineffective. For example, it has previously been suggested that one of the greatest obstacles to overcome with respect to creating the right type of education for chemical engineers, does not arise from external drivers, but in recognising and responding to internal factors - amounting to fundamental pedagogical shifts in learner behaviour and expectation [1].

\section{Methodological approach}

Our approach taken to this review is principally a case study [3] which is polygonal in nature - involving staff, students, former graduates and employers. Even though we acknowledge that students are one of many drivers of curriculum change, their voice is an increasingly powerful one [4]. In this paper, we present evidence of the student voice, which will inform curriculum review via questionnaires and interviews. Questionnaires were prepared and administered to students to solicit responses on the following five topics of interest: technology assisted learning, interactive pedagogies, assessment practices, mechanisms used to provide pastoral support and the development of skills and capabilities. These five topics had been identified as relevant in earlier focus groups with students and formed the basis of the statements making up the survey. The statements selected were guided by focus group comments where students had either highlighted causes for concerns or aspects of their experiences they were positive about - we wanted to establish what other aspects informed the main topic (for example how many students preferred interactive teaching) and whether there was consensus among students. The questionnaire was made available to students online and each year group was sent several reminders to complete the questionnaires. Students were informed that their responses would be treated anonymously, in confidence and that if they completed the questionnaire they would be consenting to the data being used for publication purposes (in line with college ethics requirements). Even though we have over 500 students on our undergraduate degree course (approximately 140 per year), in total, 189 students completed questionnaires, across all 4 years of the programme: year 1 (52), year 2 (39), year 3 (40), year 4 (22) and did not state (36). An open-comments box was made 
available following the survey questions for each of the 4 discrete topics for students to add their own comments if they so wished, which were also collated anonymously. Additionally, we have started conducting interviews with individual students. Again, an email was sent to all students across the 4-year programme seeking volunteers (they were reimbursed with $£ 10$ vouchers). As students received a financial incentive and we were faced with time constraints (student projects and exam revision), we were limited in the number of interviews we could conduct and are hoping to carry out a total of 16 interviews in total (4 students from each year group). Students were asked the following 4 questions using a semi-structured interview format: (1). Describe your experience of the programme (2). What could have been done to improve your experience? (3). What has been the most important or useful aspect of the programme and why? (4). What has been the least important or useful aspect of the programme and why? Preliminary analysis of interview data has begun. With students' consent, the interviews were recorded and transcribed in full and then emailed through to the individual students so they could be agreed. They were then re-read in detail by two individuals independently and excerpts highlighted where students had referred to any of the major themes (technology, assessment and teaching, tutorial support and wellbeing, and capabilities and skills). Once the interviews are complete, all transcripts will undergo a similar process of primary analysis followed by a secondary analysis whereby sub-themes will be highlighted and compared and contrasted with responses from the student questionnaire so our findings are more robust. We are presenting some of our preliminary data from the questionnaires for each of the topics in this paper: 


\section{Preliminary findings}

\section{The results and discussion have been presented together for ease of reading.}

\section{Technology assisted learning (Panopto ${ }^{1}$ and Sofia ${ }^{2}$ )}

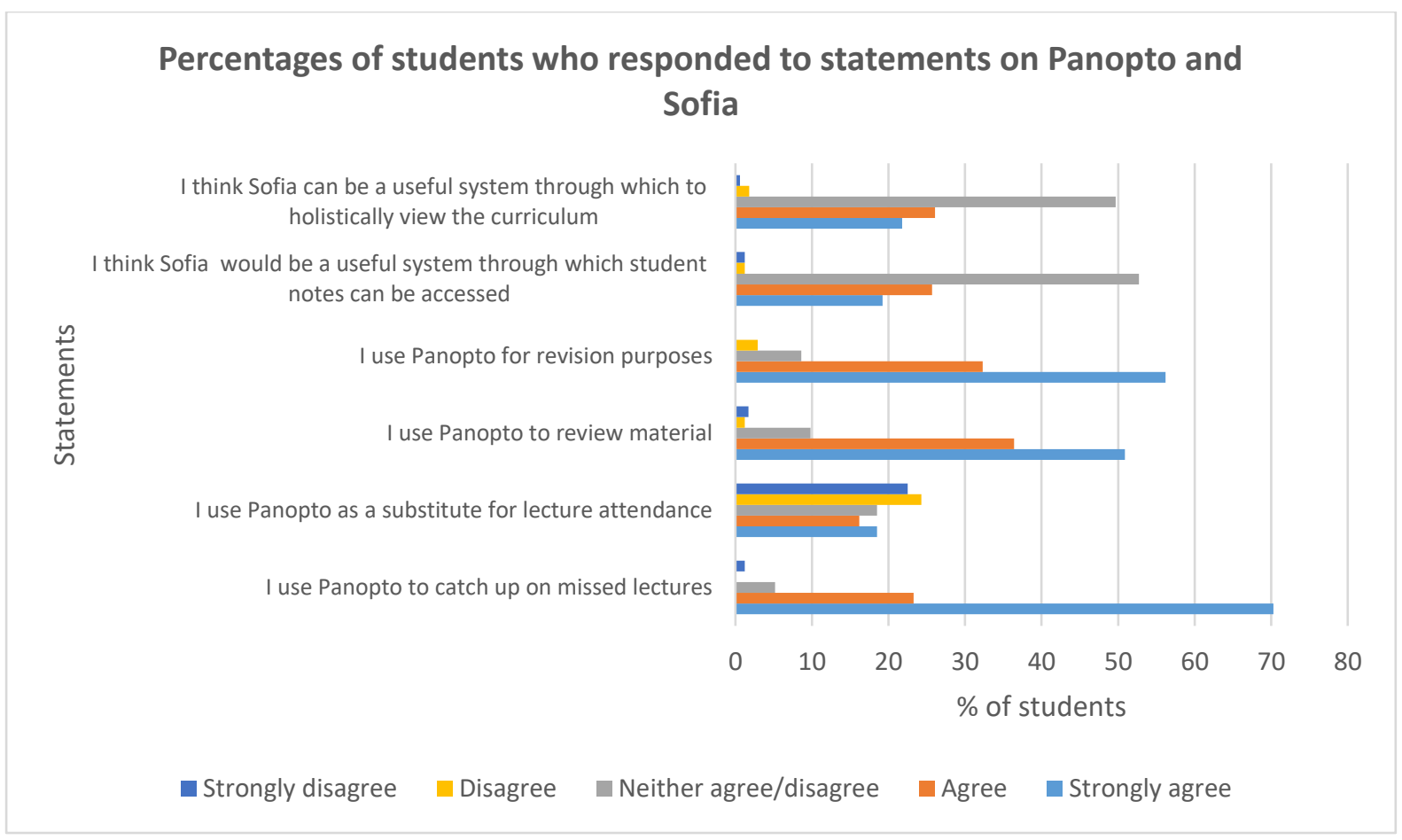

Figure 1: Graph showing percentages of students who agreed/disagreed with statements related to Panopto and Sofia

In total, 49 students added an additional comment, 15 of which highlighted the importance of Panopto. One such comment is provided:

"Panopto is essential for my studies and should be made mandatory for every lecture. After 20 minutes into a lecture I often feel left behind, confused and have useless notes to revise from. The ability to watch a lecture on Panopto, stop the recording and really consider the questions raised is so incredibly useful for my learning style."

Even though lecture video capture systems such as Panopto were initially used to prevent high dropout among students - allowing students to work through material in their own way and at their own pace, according to Figure 1, our data suggests that it is used just as readily to miss lectures. Questions naturally arise about class attendance if this is the case. Such a question has been raised in earlier research conducted by Toppin [5] who found that this was not the case and that if lectures were considered good by students, they would both be attended by students and reviewed through video lecture capture. Sofia, on the other hand, is

\footnotetext{
${ }^{1}$ Video lecture capture tool, used to record all scheduled lectures.

${ }^{2}$ Software that can be used to create a visual mapping of where key topics and associated learning outcomes exist in the curriculum and how they cross-link.
} 
an online mapping tool which is being trialled as part of the curriculum review process. Mapping tools of this nature are seen to provide the big picture view and can help teaching staff revise module and curriculum content, pointing out where in the curriculum learning gain ought to occur [6]. We are hoping to be able to engage with Sofia in a similar fashion by initially mapping learning outcomes against assessment criteria for individual modules. As yet, students have not interacted with Sofia, although as is revealed in Figure 1 more students can see the potential benefit of it than those who cannot.

\section{Interactive pedagogies and assessment practices}

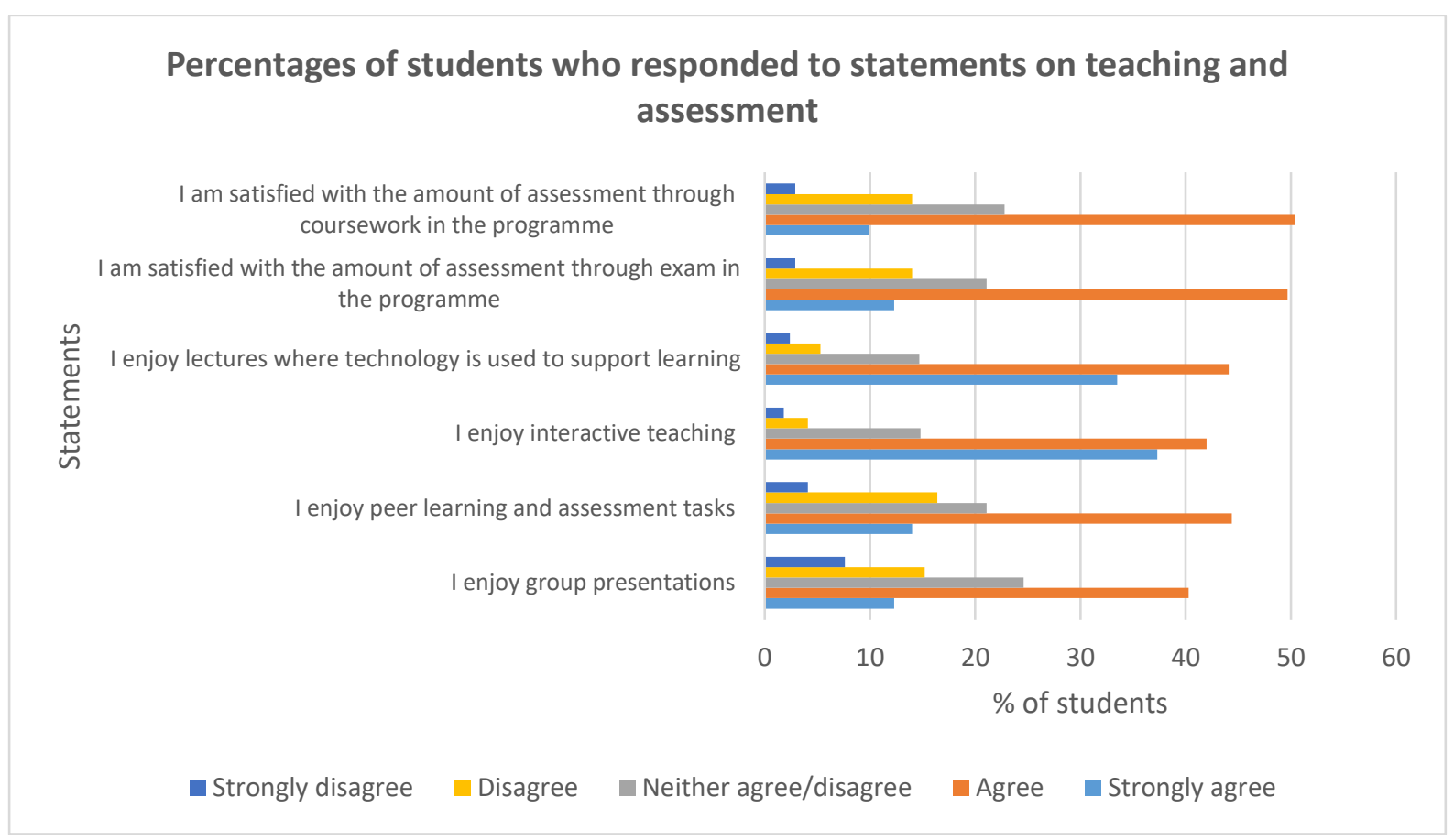

Figure 2: Graph showing percentages of students who agreed/disagreed with statements related to teaching and assessment

In total, 36 students added an additional comment, 12 of which addressed the balance between assessment via exam and assessment via coursework. One such comment is provided:

"There's a good balance between assessment through coursework and exams in the chemical engineering degree programme, however sometimes the coursework can become so time-consuming and challenging, that you end up having to cram through lectures in the holidays and catch up which can be a bit stressful."

As shown in Figure 2, even though a slight majority of students do not feel they have a good work/life balance, they either agree or strongly agree with the current balance that exists between the amount of assessment through exam (mainly end-of-year for core and fundamental subjects) and through coursework (mainly labs and various design projects). They have also expressed a preference for peer learning, suggested as a valued teaching mechanism among chemical engineering undergraduates [7], although this is actually 
contradictory to the feedback we received during earlier focus group sessions in which students commented that the teaching-learning environment was a rather competitive one and that collaboration was not always welcome or easy to achieve.

\section{Mechanisms used to provide pastoral support}

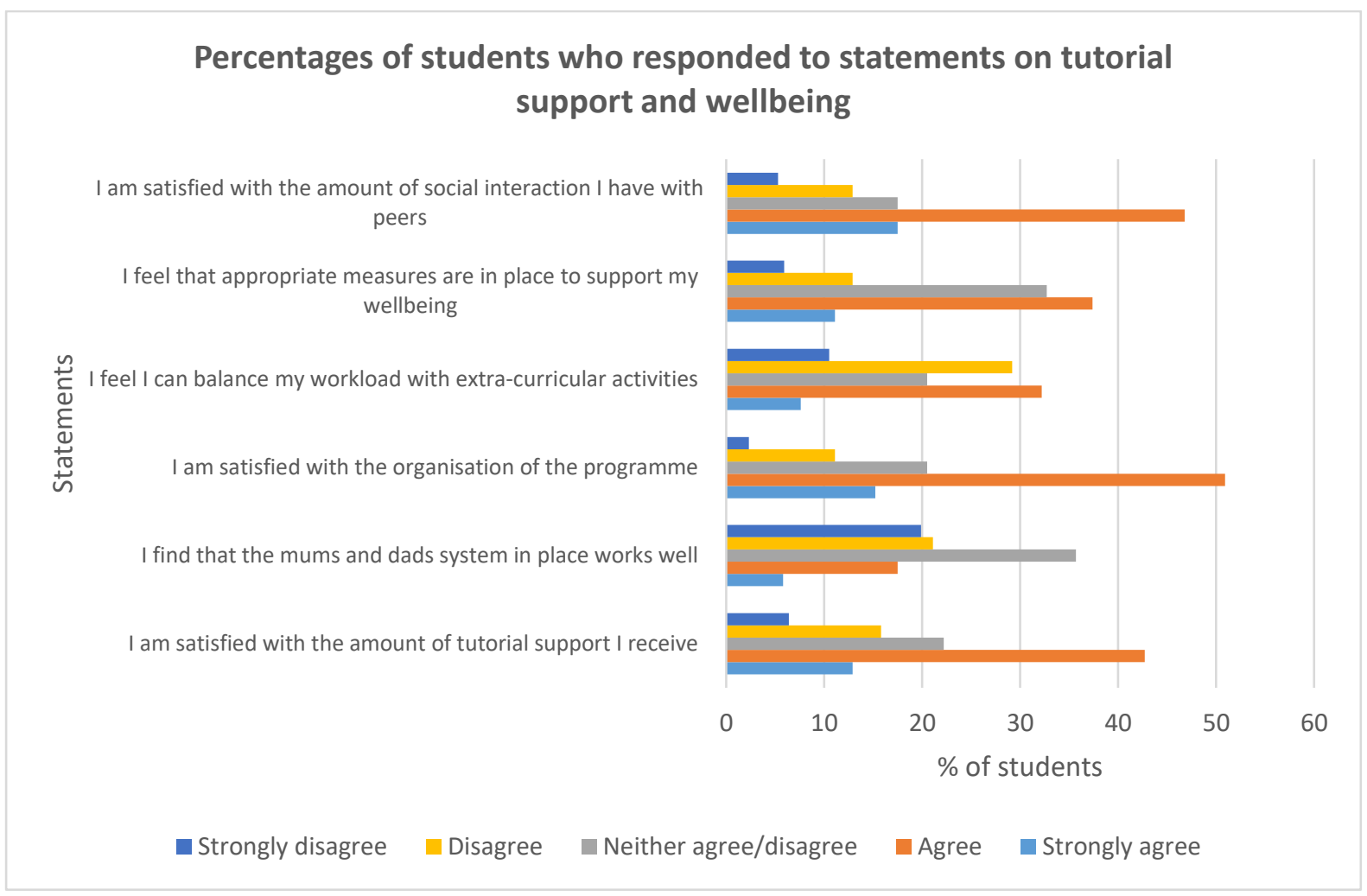

Figure 3: Graph showing percentages of students who agreed/disagreed with statements related to tutorial support and wellbeing

In total, 30 students added an additional comment, 11 of which mentioned tutorial support. One such comment is provided:

"My tutors are excellent, but they are extremely busy. Sometimes I wish I had someone who could dedicate more time (up to an hour) every month in a one-to-one meeting. I'd benefit from being able to really talk regularly about how I'm doing, and how I can reach my goals and overcome my challenges."

One of our major focuses in the department is in supporting student wellbeing, which is often correlated with assessment burden [8]. A significant proportion of respondents felt that they were not able to achieve a good balance between their academic activities and extracurricular activities or that the "mums and dads ${ }^{3}$ relationship was beneficial to them, as is represented in Figure 3 (statements 3 and 5). In relation to the first finding, the concern was previously acknowledged by the curriculum review team in our department, and one of the

\footnotetext{
${ }^{3}$ Scheme set up through the students union whereby students from the year directly above mentors one or two students from the year directly below.
} 
main purposes of the review is to create more space for students to enjoy their time at university and reflect on their learning which they feel they are currently not able to do. In terms of the 'mums and dads' initiative, additional comments from the questionnaire suggest an ad-hoc approach which achieves little tangible benefit as it lacks a coherent structure and its value is unclear.

\section{The development of capabilities and skills}

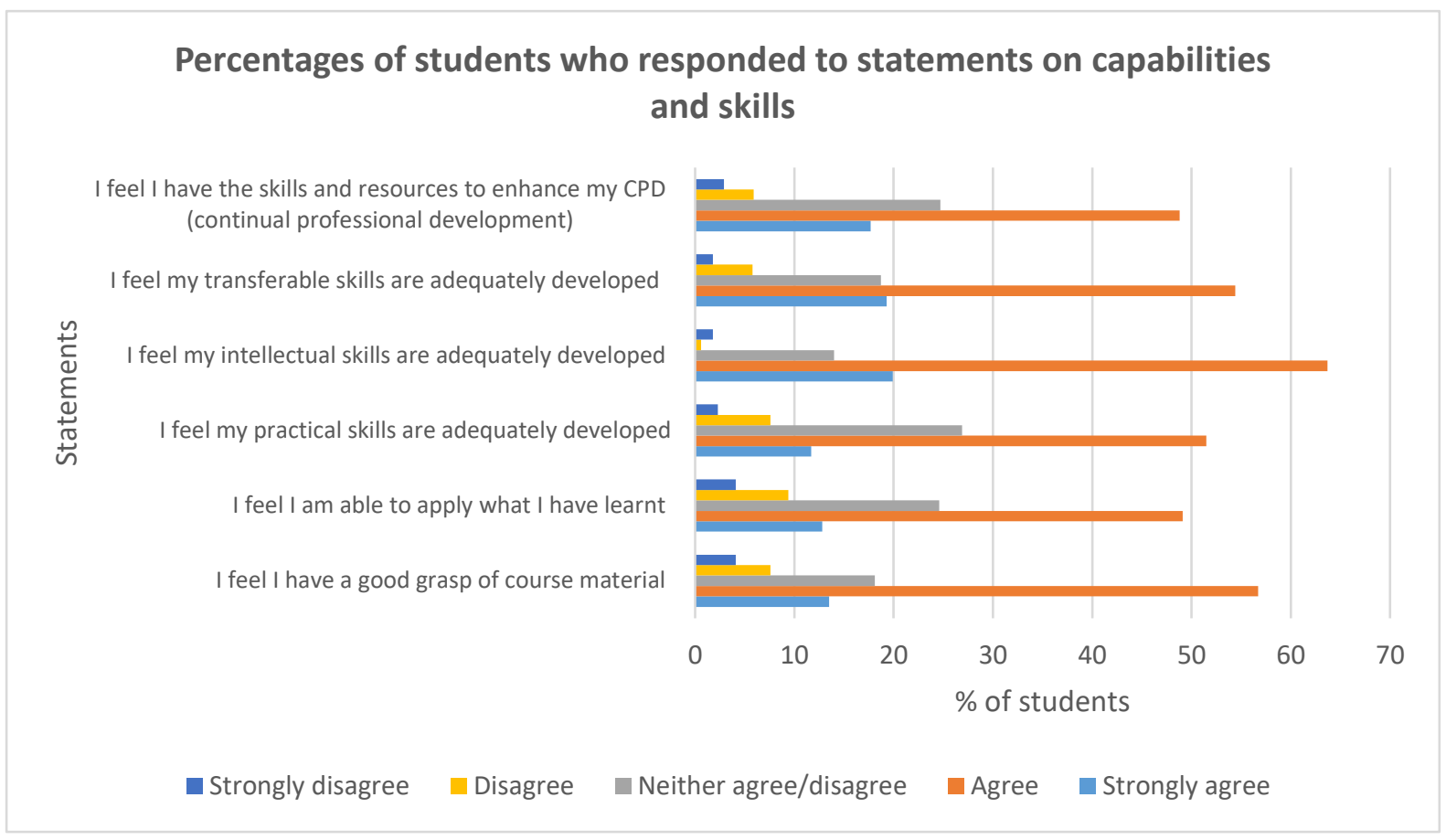

Figure 4: Graph showing percentages of students who agreed/disagreed with statements related to capabilities and skills

In total, 21 students added an additional comment, 10 of which drew attention to provision for professional skills development. One such comment is provided:

"More projects that are solely based on chemical engineering applications that are encountered in the real world would help keep perspective and interest (e.g. a Mastery project). More professional skills workshops/opportunities to practice this as part of the curriculum would help CPD and develop transferable skills."

Figure 4 shows that a high proportion of students are extremely satisfied with the skills and capabilities they acquire throughout the course of their degree programme with at least 80 students (and nearly or more than 50\% of respondents) agreeing to each of the statements. However, the additional comments point to a lack of support with respect to continual professional development. Admittedly, chemical engineering is not a subject that is taught in school so students have very little idea of what it entails until they formally start studying it at 
university. Students can enter a variety of chemical industries, such as food and drink, biotechnology and environmental engineering, although a historical survey of international chemical engineering students has also revealed an interest in financial services, especially among male students studying in the UK [9]. As a discipline, chemical engineering seems to suffer from having too large a scope in terms of a future career pathway as opposed to too narrow a one.

\section{Conclusions}

As this paper is a work-in-progress, we are unable to put forward concrete conclusions at this stage. However, we are in a position to present some insights based on students' experiences which serve as invaluable pointers for the next phase of our curriculum review. Firstly, we need to think more carefully about the technological platforms we expose our students to as they impact the ways in which students engage with learning and subsequently with us as educators. Secondly, valued and connected support mechanisms are key to ensuring students develop appropriate ways of coping with their workload which in and of itself, needs to be balanced. Finally, students need to be more exposed to employers and industrial settings so that they can further develop their professional skills.

\section{References:}

[1]. Felder, R.M., Woods, D.R., Stice J.E. and Rugarcia, A., "The future of engineering education", Chemical Engineering Education, 34(1) pp. 26-39, 2000

[2]. Gomes V.G., Barton G.W., Petrie J.G., Romagnoli J., Holt P., Abbas A., Cohen B., Harris A.T., Haynes, B.S., Langrish, T.A.G., Orellana J., See H.T., Valix M. and White D., "Chemical engineering curriculum renewal", Education for Chemical Engineers, 1 pp.116-125, 2006

[3]. Stake, R.E., "The Art of Case Study Research", Sage: Thousand Islands, London and New Delhi, 1995

[4.] Cuthbert, R., "Students as customers", Higher Education Review, 42(3) pp.3-25, 2010

[5]. Toppin, I.N., "Video lecture capture (VLC) system: a comparison of student versus faculty perceptions", Education and Information Technologies, 16(4) pp.383-393, 2010

[6]. Mazurat, R. and Schönwetter D. "Electronic curriculum mapping: supporting competency-based dental education", Journal of Canadian Dental Association, 74(10) pp.886-889, 2008

[7.] Felder, R.M. and Brent, R. "Active Learning: Models from the Analytical Sciences," ACS Symposium Series 970, Washington DC: American Chemical Society, 2007

[8.] Ansari, W.E., Stock, C., Snelgrove, S., Hu X., Parke, S., Davies, S., John, J., Adetunji H., Stoate, M., Deeny P., Philips, C. and Mabhala, A., "Feeling healthy? A survey of physical and psychological wellbeing of students from seven universities in the UK", 
International Journal of Environmental Research and Public Health, 8(5) pp. 13081323, 2011

[9.] Shallcross, D.C., "Career preferences for undergraduate chemical engineering students: results of an international survey", Trans IChemE Part D., Education for Chemical Engineers, 1 pp.30-38, 2006 